AperTO - Archivio Istituzionale Open Access dell'Università di Torino

\title{
Explaining pragmatic performance in traumatic brain injury: a process perspective on communicative errors
}

This is a pre print version of the following article:

Original Citation:

Availability:

This version is available http://hdl.handle.net/2318/158487

since 2016-10-28T11:15:34Z

Published version:

DOI:10.1111/1460-6984.12114

Terms of use:

Open Access

Anyone can freely access the full text of works made available as "Open Access". Works made available under a Creative Commons license can be used according to the terms and conditions of said license. Use of all other works requires consent of the right holder (author or publisher) if not exempted from copyright protection by the applicable law. 


\section{(6) \\ UNIVERSITÀ DEGLI STUDI DI TORINO}

This is an author version of the contribution published on:

International Journal of Language and Communication Disorders, 50, 6383

Bosco F.M., Angeleri R., Sacco K. \& Bara B. G. (2015).

Explaining pragmatic performance in traumatic brain injury: a process perspective on communicative errors.

The definitive version is available at:

La versione definitiva è disponibile alla URL:

http://onlinelibrary.wiley.com/doi/10.1111/1460-6984.12114/abstract 
Communicative errors in patients with $\mathrm{CHI}$

Communicative Errors in Patients with Closed-Head Injury:

When and Why They Fail

Francesca M. Bosco, Romina Angeleri, Marina Zettin, Katiuscia Sacco

\& Bruno G. Bara

Center for Cognitive Science, Department of Psychology, University of Turin

\section{Author's Notes}

Francesca M. Bosco, Center for Cognitive Science, Department of Psychology, University of Turin, and Neuroscience Institute of Turin; Romina Angeleri, Center for Cognitive Science, Department of Psychology, University of Turin; Marina Zettin, University of Turin, Department of Psychology and Centro Puzzle of Turin; Katiuscia Sacco, Center for Cognitive Science, Department of Psychology, University of Turin, Neuroscience Institute of Turin, and CCS fMRI Neuroradiology at Koelliker Hospital, Turin; Bruno G. Bara, Center for Cognitive Science, Department of Psychology, University of Turin, and Neuroscience Institute of Turin. 


\begin{abstract}
Purpose: The aim of the present study is to provide an in-depth description of the communicative errors made by participants with closed-head injury (CHI). Method: A group of 30 individuals with $\mathrm{CHI}$ and normal matched controls took part in the experiment. They were presented with a series of short videotaped vignettes depicting everyday social exchanges and tested on comprehension and production of different kinds of communicative acts (direct and indirect speech acts, irony and deceit). The participants' answers were evaluated as correct or incorrect. Incorrect answers were then further rated as totally incorrect or with the presence of intermediate errors.

Results: Individuals with CHI performed worse than controls on all the tasks investigated when considering correct vs. incorrect answers. Furthermore, a series of logistic regression analyses showed that group membership (CHI vs. controls) significantly predicted the occurrence of intermediate errors in responses on both comprehension and production tasks.

Conclusion: Participants with CHI tend to have marked difficulty understanding and producing different types of communicative acts, and make more intermediate errors than control participants. The findings support a theoretical framework of communication in which the comprehension and production of communicative acts are viewed as step-by-step processes rather than as "all-or-none" phenomena.
\end{abstract}


Communicative errors in patients with $\mathrm{CHI}$

\section{Introduction}

The aim of the present study is to provide an articulated description of pragmatic errors made by individuals with with closed-head injury $(\mathrm{CHI})$ in the comprehension and production of several pragmatic phenomena, i.e. direct and indirect communicative acts, deceit and irony, expressed using both the linguistic and extralinguistic modalities.

Several studies in the literature have reported a range of communicative deficits in individuals with $\mathrm{CHI}$ when tested on different pragmatic phenomena. The term pragmatics refers to a number of communicative behaviors that are concerned with how language is used to convey meanings in context (see Levinson, 1983), and in particular with the relationship between what speakers say and what they mean or intend to communicate (e.g., Gibbs, 1999). Individuals with CHI have difficulty going beyond the literal meaning of utterances (e.g., Winner \& Gardner, 1977), and in understanding what is implied, as in the case of the comprehension of indirect speech acts and irony (Bara, Tirassa, \& Zettin, 1997), sarcastic utterances (McDonald \& Pearce, 1996), humor (Braun, Lissier, Baribeau, \& Ethier, 1989; Docking, Murdoch, \& Jordan, 2000), and commercial messages which require inferential processes in order to be understood (Pearce, McDonald, \& Coltheart, 1998). Individuals with CHI are also impaired in the production of specific types of verbal communicative acts, for example, in producing correct requests (McDonald \& Van Sommers, 1993), or in giving the interlocutor sufficiently detailed information (McDonald, 1993). Numerous studies have also documented a variety of subtle communicative impairments in conversational discourse (e.g., Coelho, 2002; Coelho, Youse, Le, \& Feinn, 2003; Johnson \& Turkstra, 2012; Togher, Power, Tate, McDonald, \& Rietdijk, 2010; Turksra, Brehm, \& Montgomery, 2006). At the level of discourse, individuals with 
Communicative errors in patients with $\mathrm{CHI}$

CHI may produce narratives with increased errors of cohesion and coherence (e.g., Hartley \& Jensen, 1991; Marini, Galetto, Zampieri, Vorano, Zettin, \& Carlomagno, 2011), and may show difficulties in the macrolinguistic organization of their narratives and in conveying appropriate information at the level of story structure organization (e.g., Carlomagno, Giannotti, Vorano, \& Marini, 2011).

Dardier and colleagues (2011) recently conducted a detailed analysis of the pragmatic aspects of language use by individuals with traumatic brain injury (TBI), examining both comprehension (i.e., hints, direct, and indirect requests) and production ability (i.e., conversation) during an interview situation. The authors showed that the pragmatic skills of persons with TBI vary across tasks: patients demonstrated weakness (in topic maintenance) but also strengths (in turn-taking, comprehension of requests and hints).

The ability to comprehend and produce communicative acts using the extralinguistic modality is also impaired in these individuals (Bara, Cutica, \& Tirassa, 2001). Rousseaux and colleagues (2010) evaluated both verbal and non-verbal aspects of communication in individuals with TBI in dyadic interactions and found that, during the chronic phase, they showed marked difficulties in speech outflow and pragmatic language, i.e., responding to open questions, presenting new information and introducing new themes, organizing discourse and adapting to interlocutor language. However, the authors did not exclude patients with performance below the cut-off scores on aphasia testing, and this could have contributed to explaining their difficulties with verbal communication. As far as non-verbal communication is concerned, patients were impaired in understanding and producing gestures, in affective expressivity, in feedback management and pragmatics (i.e., prosody, orienting gaze, using regulatory mimogestuality, and turn-taking). 
Communicative errors in patients with $\mathrm{CHI}$

Angeleri and colleagues (2008) provided a comprehensive assessment of communicative deficits in TBI patients, evaluating different expressive modalities, encompassing linguistic, extralinguistic and paralinguistic aspects. The authors showed that individuals with TBI are impaired, to varying degrees of severity, in the comprehension and production of a wide range of pragmatic tasks, such as direct speech acts, (sentences that communicate exactly and literally what the speaker intends to say), indirect speech acts (sentences that communicate to the listener more than what the speaker is actually literally saying), irony, deceit, and sensitivity to the violation of Grice's maxims.

The ability to recognize, interpret, and express communicative intentions plays a key role in human social life: the integration of these factors requires social cognition - the ability to construct representations of the relations between oneself and others, and to use those representations flexibly to guide social behavior (e.g., Adolphs, 2001). This ability to coordinate cognition, emotion regulation, and social competence in novel or complex situations requiring goal-directed behavior is considered a part of executive functioning (e.g., Lezak, Howieson, \& Loring, 2004). Impaired executive functioning is associated with focal and diffuse frontal lesions (e.g., Eslinger, Zappalà, Chakara, \& Barrett, 2007; Mozeiko, Le, Coelho, Krueger, \& Grafman, 2011); in individuals with TBI, difficulties in social cognition may be particularly evident when the injury involves the frontal lobes (Chapman, 1997). Various studies have reported impairments in social aspects of communication after TBI, including difficulty in discriminating social cues, empathy, theory of mind, and perspective-taking (e.g., Bibby \& McDonald, 2005; de Sousa et al., 2010; Turkstra, McDonald, \& DePompei, 2001; Ylvisaker, 1998; McDonald, 2012). 
Communicative errors in patients with $\mathrm{CHI}$

It is thus well-established that patients with CHI have difficulty interpreting and responding appropriately to a range of communicative and social cues, including verbal language, prosody, and extralinguistic information. Hence, a pragmatic approach to the assessment of clinical language problems has led to the development of a number of evaluation measures.

Pragmatic measures share the multidimensional perspective of both linguistic and non-linguistic measures and include, among others, the Pragmatic Protocol (Prutting \& Kirchner, 1987), the Profile of Communicative Appropriateness (PCA; Penn, 1988), and the Communicative Abilities in Daily Living (CADL; Holland, 1980; CADL-2; Holland, Frattali, \& Fromm, 1998). All the measures are able to identify specific areas of communicative impairment observing the patients' natural conversation (Pragmatic Protocol; PCA) or involving them in role-play activities reproducing everyday social situations (CADL-2).

“The Awareness of Social Inference Test” (TASIT; McDonald, Flanagan, Rollins, \& Kinch, 2003), divides the comprehension of social exchanges into different components. TASIT assesses both the ability to make judgments about the mental and emotional state of the speakers (TASIT Part I) and the ability to interpret social inference (TASIT Part II). In the social inference test, to capture distinct facets of the inferential process, the comprehension of verbal exchanges is assessed via four questions: (a) thinking question, to determine whether individuals are capable of making judgments about what different speakers know when interpreting social inference; (b) doing question, to assess the ability to judge speaker intention; (c) feeling question, to determine whether the patient is capable of assessing feelings based on expression or intonation; and (d) saying question, to determine the ability to detect the intended meaning of the literal content. In the case of TASIT, the distinct 
Communicative errors in patients with $\mathrm{CHI}$

scores for the different kinds of inferential judgments about the speakers and their internal states are generally equivalent in difficulty, and are not intended to represent a hierarchical structure.

In line with this perspective, the present study aims to analyze pragmatic abilities in individuals with $\mathrm{CHI}$ by parceling out the comprehension and production of communicative acts into distinct components, with the expectation that participants with $\mathrm{CHI}$ will show different levels of performance, i.e. they will make different intermediate errors, by failing at different steps of the process. Managing conversation involves a number of steps, each of which may possibly represent a different level of skill in comprehension/production. In particular, we parceled out the comprehension and production of communicative acts into distinct hierarchical components (i.e., from the easiest to the most demanding).

The novelty of the present study is that it investigates the communicative ability of individuals with $\mathrm{CHI}$ from a new perspective, by (i) providing a robust theoretical background that supports the use of these components in clinical practice, (ii) examining both the comprehension and the production of communicative acts, and (iii) including both the linguistic and the extralinguistic expressive modalities.

To achieve these goals, the linguistic and extralinguistic scales of the Assessment Battery of Communication-ABaCo (Sacco et al., 2008; Bosco, Angeleri, Zuffranieri, Bara, \& Sacco, 2012) were used in the present study. The battery was built on the basis of the Cognitive Pragmatics theory, which is able to predict and explain the development of pragmatic ability in children (Bosco, Bara \& Bucciarelli, 2004; 2006; Bosco \& Bucciarelli, 2008) and the decay of pragmatic performance in subjects with traumatic brain injury (Bara, Tirassa \& Zettin, 1997; Angeleri et al. 2008). The battery was chosen for its capability to identify a wide 
Communicative errors in patients with $\mathrm{CHI}$

range of pragmatic deficits, as shown in a previous study in a group of 21 participants with CHI (Angeleri et al., 2008). Administering the same test increased the likelihood of detecting a sufficient number of erroneous answers to analyze. Furthermore, the idea of the present study was to analyze both the comprehension and production of communicative acts, and the two selected scales of the battery provided specific items for testing both these abilities. For the present study, the sample was extended to include 30 participants with $\mathrm{CHI}$, and the analyses were performed in a completely new way with respect to previous research.

\section{The Comprehension and Production of a Communicative Act}

In the philosophy of language, communication consists of an agent's intentional action overtly aimed at the modification of a partner's mental states (Austin, 1962; Searle, 1969; Grice, 1975). A mental state is a theoretical construct created in order to describe, predict and explain human behavior (Premak \& Woodruf, 1978). Mental states are mental representations such as knowledge, beliefs, sharedness, expectancies, desires, intentions, hopes, fears and so on (Tirassa, Bosco \& Colle 2006a, 2006b; Bosco, Colle, Bono, Ruberti \& Tirassa, 2009). Intentional communication consists in a person's action that aims to modify one or more of the partner's internal states, e.g. the actor may intend to share something with his/her partner, to induce him/her to believe something, to induce him/her to do something, and so on.

Within the linguistic domain, Wigand (1999) proposed the process of "coming to understanding" in dialogical interactions as a model of harmonious communication: the author considers non-comprehension and misunderstanding as an integral part of the comprehension process rather than as a simple breakdown (see also Dascal, 1985; Kreutz \& Roberts, 1993). 
Communicative errors in patients with $\mathrm{CHI}$

Underlying the idea that non-comprehension and misunderstanding are intrinsic parts of the communicative process is the Principle of Cooperation (Grice, 1957), according to which conversations are cooperative efforts where the participants recognize a common purpose. The Principle of Cooperation may be violated intentionally or unconsciously, to convey a different meaning than what is literally spoken. A classic example is deceit, where the speaker says something that is not true in order to deceive her/his listener, violating the Maxim of Quality ("Do not say what you believe to be false") included in the Principle of Cooperation. In the case of irony, there is still a violation of the same Maxim (i.e., the speaker says something untrue, opposite to the literal meaning), but for a purpose that is totally different from deceit. In the present study, Grice's notion of cooperation was used to explore the comprehension and production of different communicative acts; for example, in tasks involving the comprehension of deceit and irony, the idea was to assess sensitivity to the violation (i.e., the speaker didn't tell the truth), and understanding of the communicative purpose (i.e., why the speaker didn't tell the truth).

Within this general framework, Airenti, Bara and Colombetti (1993a) proposed the theory of Cognitive Pragmatics to deal with the cognitive processes involved in comprehending and producing communicative acts (for the most recent development of the theory, see Bara, 2010). According to this theory, the comprehension/production of a communicative act occurs in a sequence of distinct steps:

Expression act. The partner reconstructs the actor's mental state starting from the literal act. The conversation game in the present phase sets up the task of recognizing the actor's expression act. Note that the use of the terms actor and partner 
Communicative errors in patients with $\mathrm{CHI}$

- instead of speaker and hearer - was intended to highlight that the theory refers to both linguistic and extralinguistic communication.

Actor's meaning. The partner recognizes the meaning of the utterance when he reconstructs the actor's communicative intention.

Communicative effect. The communicative effect on the partner is the entire set of the partner's mental states, acquired or modified as a result of the communicative intentions expressed by the actor.

At this point the partner produces the intention he wants to communicate in his response; it is the result of the effects of the communicative act.

Response. Then the partner produces an overt communicative response (an action or an utterance), as an answer to the actor's communicative act.

The comprehension/generation process is continuous in that the generation of an answer on the part of the partner may constitute the starting point for a new comprehension process on the part of the actor, who in turn will produce a new communicative act.

Communicative errors or failures - that is, unsuccessful attempts to produce an intended effect in the interlocutor - may occur in any phase of the communicative process (Airenti, Bara, \& Colombetti, 1993b; see also Bosco, Bucciarelli, \& Bara, 2006, and Bosco, Bono, \& Bara, 2012). In the theoretical framework adopted for this study, a successful communicative act is thus not an "all-or-none" phenomenon but is, by contrast, a graduated process that can be fully or partially completed.

The present paper explores the possibility that, even if individuals with $\mathrm{CHI}$ may fail to fully comprehend or produce the various communicative tasks investigated (i.e., to achieve the communicative effect phase), they may nonetheless demonstrate an "intermediate level" of comprehension/production ability, 
Communicative errors in patients with $\mathrm{CHI}$

corresponding to the achievement of the expression act or actor's meaning phase in the comprehension/production process described above.

To investigate this aspect, an in-depth analysis of participants' performance on the linguistic and extralinguistic scales of the Assessment Battery for Communication (Sacco et al., 2008) was conducted. Focusing on participants' answers traditionally coded as "wrong", a distinction was made between "totally wrong" and "intermediate errors". In particular, the latter cases, in which participants failed to achieve the full comprehension/production of a communicative act were further analyzed to assess the level at which the comprehension/production process was interrupted. Accordingly, the participants' responses were considered as "presence of intermediate errors" when they failed the final comprehension/production step, but had passed one of the previous steps of the comprehension/production process, and as "totally wrong" when they failed all steps. The occurrence of intermediate errors was then described and quantified with the aim of exploring the hypothesis that participants with $\mathrm{CHI}$ produce "intermediate errors" more frequently than those without brain injury in the control group.

\section{Method}

\section{Participants}

Two groups participated in the present study: a group of individuals with CHI and a normal control group. The CHI group consisted of 30 participants with closedhead injury (24 male/6 female) ranging in age from 20 to 68 years $(M=37.13 ; S D=$ 11.36); their education ranged from 5 to 18 years of schooling $(M=11.1 ; S D=3.29)$. Based on clinical evaluation, participants were classified as victims of moderate to severe head injury. The participants with CHI were recruited through different rehabilitation centers in Geneva and in Turin (Italy) following head injury. The time 
Communicative errors in patients with $\mathrm{CHI}$

after onset ranged from 3 to 252 months $(M=60.1 ; S D=64.21)$. All participants with CHI had sustained their injury in traffic accidents, all resulting in closed-head injury. All had traumatic brain injury characterized as diffuse; however, most participants also suffered from focal damage resulting from inertial forces in different areas of the brain, and detected by MRI scan. Table 1 presents the participants' clinical details.

- Insert Table 1 about here -

At the time of the study, all participants with CHI were in a post-acute phase; they were living at home with their caregiver (partner/family). Subjects with CHI had to meet the following inclusion criteria to participate in the study: (1) be at least 18 years of age; (2) be at least 3 months post-brain injury; (3) be Italian native speakers; (4) provide their informed consent; and (5) have adequate cognitive and communicative skills, tested by the achievement of a cut-off score in the following neuropsychological tests: MiniMental State Examination (MMSE, Folstein, Folstein, \& McHugh, 1975; cut-off: 24/30); denomination scale of the Aachener Aphasie Test (AAT, Huber, Poeck, Weniger, \& Willmes, 1983; cut-off: no deficit) and Token Test (De Renzi \& Vignolo, 1962; cut-off: 5/6). None of the participants reported a history of neurological disease, psychiatric illness, previous head injury, stroke, antipsychotic medication use or substance abuse disorder. All participants were right-handed. The control group consisted of 30 healthy individuals, closely matched to the participant with $\mathrm{CHI}$ in terms of gender (24 male/ 6 female), age $(M=36.47 ; S D=10.95 ; t(58)=$ $.23, p=.82,95 \% \mathrm{CI}[-5.10,6.43])$ and years of education $(M=10.8 ; S D=3.23 ; t(58)$ $=.36, p=.72,95 \% \mathrm{CI}[-1.39,1.99])$. None of them had other brain damage or a history of neurological disorders. The Battery protocol was approved by the Ethics 
Communicative errors in patients with $\mathrm{CHI}$

Committee of the Department of Psychology, University of Turin (Italy).

\section{Material}

The linguistic and extralinguistic scales of the Assessment Battery of Communication (ABaCo, Sacco et al., 2008) were administered to the participants. Only the linguistic and extralinguistic scales - and not the other scales included in the Battery (i.e., paralinguistic, context and conversational scales) - were analyzed because the linguistic and extralinguistic scales investigate the most complex, and for the goal of the present research - most interesting pragmatic phenomena, namely: standard (indirect) communicative acts, deceit, and irony. Each scale is made up of 24 items ( 8 standard communicative acts, 8 deceits, and 8 ironies), equally divided into comprehension (12 items) and production tasks (12 items), for a total of 48 items. All the tasks consisted in videotaped scenes (lasting 20-25 seconds) where two actors were engaged in communicative exchanges. For the comprehension tasks, the two actors performed an everyday communicative exchange that might typically occur between a couple, two colleagues, or two friends, and the participants were asked to understand what happened, while for the production tasks only one actor performed a communicative act and the participants were asked to complete the dialogue from the interlocutor's perspective (see also the Procedure section). On the linguistic scale all communicative acts were performed linguistically and comprised a controlled number of words (range: $7 \pm 2$ ), while on the extralinguistic scale all communicative acts were performed through gestures. The tasks were randomized across participants. Some examples of the tasks are provided in Appendix B.

\section{Procedure}

Both the neuropsychological battery and the experimental protocol were administered individually to the participants, during two subsequent sessions each 
Communicative errors in patients with $\mathrm{CHI}$

lasting about one hour. Participants with CHI were tested at their rehabilitation centers, while those in the control group were tested at home.

\section{Comprehension task.}

The examiner showed the participants short videos where two agents were engaged in a communicative interaction: the actor asked his partner a question and the partner replied. The participants had to understand the partner's communicative act. On the linguistic scale the actors communicated verbally, whereas on the extralinguistic scale they communicated through gestures alone.

\section{Production task.}

The examiner showed the participants short videos where two agents were engaged in a communicative interaction: the actor said something to the partner, the video stopped and the participants were asked to answer the actor from the partner's perspective. On the linguistic scale the communicative interaction occurred in the linguistic modality and the participants had to reply verbally. On the extralinguistic scale the actor performed communicative gestures without any linguistic support and the participants had to reply using gestures alone.

To summarize, the experimental protocol used for this study comprised both the linguistic and extralinguistic scales of the $\mathrm{ABaCo}$, which encompass both linguistic and extralinguistic modalities, including standard, deceit, and irony tasks. The tasks were created to be as similar as possible to everyday interactions, and to reflect participants' communicative performance in daily life. We are aware that the experimental tasks may have required some metacognitive and metalinguistic reasoning, which played an important role in participants' understanding of the situations that were presented; this cannot be avoided when using videotaped vignettes depicting social interactions. However, since all the tasks presented in the 
Communicative errors in patients with $\mathrm{CHI}$

study required a similar level of metacognitive reasoning, there is no reason to expect systematic effects on performance for the different tasks.

\section{Scoring procedure}

The experimental sessions were video-recorded. The participants' performance was coded off-line from the videotapes by two independent judges, blind with respect to the aims of the research. The two judges recorded the participants' scores on specific score sheets while watching the video-recorded experimental sessions.

The following dimensions were used to score the participants' responses:

1. Expression act

2. Actor's meaning

3. Violation

4. Purpose

These specific dimensions correspond to specific phases of the comprehension/generation process previously described (Bara, 2010; see the "Comprehension and production of a communicative act" paragraph), and to the respect vs. violation of Grice's Principle of Cooperation (Grice, 1989), and were used to guide the raters and ensure accurate scoring (see Appendix A for a schematic representation of these dimensions). With respect to the comprehension/production process derived from the Cognitive Pragmatics Theory described above, the original final step (i.e., communicative effect) was further divided into two separate steps (violation of cooperation and purpose of violation), in line with Grice's Principle of Cooperation (Grice, 1989). From a procedural point of view, each scoring dimension corresponds to a specific question that the examiner asked the participant while administering the battery: based on the participant's answers to each of these questions, the raters were able to ascertain whether they had passed the corresponding 
Communicative errors in patients with $\mathrm{CHI}$

dimension $(1=$ passed; $0=$ not passed $)$. For each dimension passed the answer received a score of 1 . Appendix B reports some examples. The following section provides a detailed description of each specific dimension used to guide the scoring process.

\section{Comprehension task dimensions score.}

Expression act. The participant passed the dimension if s/he recognized what the actor expressed, i.e. the content of the expression act through which the actor grasped her partner's attention. Simply repeating what the actor said (echo) was not sufficient to demonstrate comprehension; participants had to produce at least a paraphrase as proof of actually having understood the expression. For example, supposing the actor in the videotaped scene says "It wasn't my fault" in order to avoid a punishment: the examiner then asked the participant: "What did the actor mean?"; if the participant answered "It wasn't my fault" (echo), that was not sufficient to establish s/he had actually recognized the expressed content; thus the participant had to be evaluated on the basis of the following in-depth question "What does that mean". By contrast, if the participant answered "That it wasn't his fault” (paraphrase), $\mathrm{s} /$ he was deemed to have recognized the expressed content and thus passed the dimension. On the extralinguistic scale, simple repetition refers both to the repetition of the same gesture performed by the actor and to the linguistic echo. For example, supposing the actor in the scene asked "Will I see you later?" and the partner performed the "OK" gesture in reply: if the participant simply repeated the same gesture or uttered "OK", these were considered mere repetitions; by paraphrasing a gesture we refer to a minimal explanation of the gesture, such as "Yes, I'll see you later". 
Communicative errors in patients with $\mathrm{CHI}$

Actor's meaning. The participant passed the dimension if s/he explained what the utterance/gesture implied or presupposed. For example, supposing the actress in the vignette says "I'm glad that you appreciated my effort" in response to her friend's question: "Who cooked the delicious dinner?"; the examiner then asked the participant: "What did the actress mean?"; if the participant answered "That she's happy that her effort was appreciated", that was not sufficient to establish that s/he had recognized the actor's meaning; the examiner then asked "What does that mean?", and if the participant also described that the sentence implied that she was the one who cooked the dinner, s/he was deemed to have recognized the actor's meaning and thus passed the corresponding dimension.

Violation of cooperation (truthfulness). The participant passed the dimension if $\mathrm{s} /$ he explained that what the actor said was not true (or not serious) or, in the case of irony, that the actor was communicating more than what was literally said.

Purpose of violation. The participant passed the dimension if s/he explained the reason why the actor produced her communicative act, for example if s/he explained that the actor expressed something false in order to hide her guilt (deceit) or as a joke (irony).

Please note that in the majority of the experimental studies investigating pragmatic skills in participants with TBI (see for example Bara, Tirassa \& Zettin, 1997; Bara, Cutica \& Tirassa, 2001; Angeleri et al. 2008; Dardier et al. 2011), a wrong answer to this last dimension (that we have called purpose of violation but that may, of course, be described by other researchers using other labels having a similar conceptual meaning) is usually regarded as evidence of complete failure on the task. The previous dimensions of the comprehension/production process are typically collapsed into this final one. Based on the assumption that such different dimensions 
Communicative errors in patients with $\mathrm{CHI}$

correspond to specific phases in the comprehension of a communicative act, the present study aims to investigate these dimensions separately, in order to clarify exactly where in the comprehension process the impairment arises.

It is important to highlight that not all the pragmatic phenomena investigated required the same dimensions of analysis: as displayed in Appendix A, for example, the comprehension of a standard communicative act does not require any violation of cooperation (i.e., the actor depicted in the vignette told the truth), nor any purpose of violation (i.e., no intention to deceive, nor to be ironic), while the comprehension of a deceit requires sensitivity to the violation of cooperation (i.e., the actor told a lie), and understanding of the purpose of the violation (i.e., the intention to deceive).

\section{Production task dimensions score.}

The dimensions for the production of communicative acts are listed below.

Expression act. The participant passed the dimension if she/he produced a communicative act that was congruent with respect to the test question. The act produced had to be an utterance on the linguistic scale, or a gesture on the extralinguistic scale.

Actor's meaning. The participant passed the dimension if she/he produced a communicative act that was plausible with respect to the communicative context, and if there was a logical connection between the patient's answer and the context shared by the participants in the interaction. In other words, the act had to be unambiguous and easily understood by the interlocutor, i.e. the rater had to find an answer to the test question in the act. For example, suppose that, in reply to the question "What would you like to do this afternoon?", the participant answered "I'd like to go to Mars": this answer is consistent with the question (expressed content), since indicating a place where one would like to go is consistent with a question about what 
Communicative errors in patients with $\mathrm{CHI}$

one would like to do, but it is unclear and the interlocutor would not understand what the participant intended to communicate; thus the answer passed the expressed content dimension, but not the speaker's meaning dimension, and we therefore considered this as an intermediate error. In contrast, "I'd like to go to the cinema" is a response that is both consistent and plausible, and we considered it a fully correct response. On the extralinguistic scale, sharedness also concerns, for example, the amplitude of the gesture: the performed gesture has to be sufficiently ample and clear so that the interlocutor comprehends its meaning.

Violation of cooperation and purpose of violation. In assessing the production of communicative acts, the violation of cooperation (truthfulness) and the purpose of violation (deceit or irony) are considered conjointly, because they cannot be evaluated independently in the participants' answers (i.e., when the participant correctly produces a deceitful or ironic utterance, $\mathrm{s} / \mathrm{he}$ necessarily produces a violation of cooperation with the purpose of deceiving or being ironic, unlike in comprehension tasks, where a participant may possibly understand the violation of the actor's communicative act but not her/his purpose). Considered together, the two dimensions correspond to the communicative effect phase in the comprehension/generation process described in the Cognitive Pragmatics theory, but to avoid confusion with respect to the dimension used for scoring the comprehension task, the labels Violation of cooperation and purpose of violation were maintained in this study. The participant passed the dimension if $\mathrm{s} /$ he produced a communicative act fulfilling the requested goals for the communicative phenomenon in question. In the case of deceit, the participant had to say (on the linguistic scale) or communicate with a gesture (on the extralinguistic scale) something that was not true, with the purpose of hiding her/his 
Communicative errors in patients with $\mathrm{CHI}$

guilt/deceit. In the case of irony, the participant had to say or communicate something with the aim of joking or making fun.

Please note that, as for comprehension, a wrong answer to this last dimension is usually regarded in the literature as proof of complete failure on the production task (see for example Bara, Tirassa \& Zettin, 1997; Bara, Cutica \& Tirassa, 2001; Angeleri et al. 2008; Dardier et al.). The intent of the present study is to further analyze the incorrect answers detected at the previous level.

Finally, it is also important to note that the dimensions described above occupy hierarchical positions: passing one dimension presupposes having passed all the previous ones. This is based on the assumption that the comprehension and production of a given communicative act require a series of sequential inferential steps (see the Introduction section). For example, comprehending the speaker's meaning implies having previously recognized the expressed content. Thus, if the participant immediately gives an answer that demonstrates an understanding of the speaker's meaning, then the rater also considers the expressed content as passed.

\section{Results}

\section{Reliability}

Cohen's kappa procedure was used to investigate consistency of the scoring of participants' responses by the two independent judges.

The $k$ value was .89 for the TBI group and .91 for the control group, indicating almost perfect agreement (Landis \& Koch, 1977).

\section{Overview of Communicative Performance of "Full Comprehension"}

The results showed that participants with $\mathrm{CHI}$ exhibited communicative deficits on all pragmatic tasks compared to normal controls. Statistical analyses were performed by including only the final scoring dimension, in line with the usual coding 
Communicative errors in patients with $\mathrm{CHI}$

approach in the current experimental literature (e.g., Angeleri et al., 2008; Dadier et al., 2011). This made it possible to evaluate the participants' general pragmatic performance, taking into account their achievements on the complete tasks (i.e., standard communicative acts, deceits, and ironies). In the next section (see Scaling of Communicative Dimensions - Intermediate Errors), the different components that constitute communicative acts will be considered, and each single scoring dimension will be examined.

As a general overview, the CHI group performed worse than healthy controls in both the linguistic and the extralinguistic modalities (see Table 2). On the linguistic scale, participants with CHI performed worse than healthy controls on both comprehension $(t(58)=7.03, p<.0001, d=-1.85)$ and production tasks $(t(58)=4.52$; $p<.0001, d=-1.19)$, as well as on the extralinguistic scale, where they performed worse on both comprehension (T Test: $t(58)=6.21 ; p<.0001, d=-1.63)$ and production tasks (T Test: $t(58)=5.39 ; \mathrm{p}<.0001, d=-1.41)$.

- Insert Table 2 about here -

Performance by participants with CHI and healthy controls also differed on each pragmatic task investigated ( $t$ ranging from 5.51 to 2.69 , p ranging from .009 to $<.0001)$. Table 3 displays scores obtained by the $\mathrm{CHI}$ and control groups.

- Insert Table 3 about here -

In the CHI group, no correlations were found between age, years of education, time post-injury, and scores on pragmatic tasks $(-.08<r<.1 ; .6<p<.66)$. 
Communicative errors in patients with $\mathrm{CHI}$

\section{Scaling of Communicative Dimension (Intermediate Errors)}

In this section the pragmatic performance of participants with $\mathrm{CHI}$ is analyzed in a new way, by examining the different dimensions that constitute the communicative acts.

The following dimensions were taken into account in scoring participants' answers on production and comprehension tasks (see the Scoring section and Appendix A):

- Expression Act (EA)

- $\quad$ Actor's Meaning (AM)

- Violation of Cooperation (VC)

- $\quad$ Purpose of Violation (PV)

Since the above-listed scoring dimensions were hierarchically created (i.e., a correct response to one dimension implies correct responses to all previous dimensions), it is possible to identify specific patterns of responses. Table 4 summarizes the possible patterns of responses.

- Insert Table 4 about here -

The diagram depicted in Table 4 provides all the potential patterns of occurrence of responses for comprehension and production tasks.

More specifically, Table 4 reports the predicted patterns of responses by indicating passed dimensions with a “+” and failed dimensions with a “-”. So, for example, considering the case of "deceit and irony comprehension", the following cases were possible:

- Pattern I (totally wrong — no intermediate errors): the participant failed all 
the scoring dimensions, i.e., her/his answer obtained " 0 " in all the four dimensions (expression act, actor's meaning, violation, and purpose). This pattern was labeled as "totally wrong" as the participant did not pass even an initial step of comprehension of the communicative act.

- Pattern II (intermediate errors) = the participant passed the expression act dimension, but failed the following dimensions (i.e., actor's meaning, violation, and purpose). Pattern II is the first of the three intermediate error patterns, because the participant obtained a score of " 1 " in the first intermediate dimension (i.e., expression act).

- Pattern III (intermediate errors) = the participant passed both the expression act and the actor's meaning dimension, but failed the following dimensions (i.e., violation and purpose). Pattern III is the second of the three intermediate error patterns, because the participant obtained a score of " 1 " in the first two intermediate dimensions (i.e., expression act and actor's meaning).

- Pattern IV (intermediate errors) = the participant passed the expression act, the actor's meaning, and the violation dimensions, but failed the following dimension (i.e., purpose). Pattern IV is the last of the three intermediate error patterns possibly occurring in the comprehension of deceit and irony, because the participant obtained a score of " 1 " in all the three intermediate dimensions (i.e., expression act, actor's meaning, and violation).

- Pattern V (fully passed-no intermediate errors) = the participant passed all the scoring dimensions, i.e., her/his answer obtained a score of " 1 " in all the four dimensions (expression act, actor's meaning, violation, and purpose). This pattern was labeled as "fully passed" because the participant succeeded 
Communicative errors in patients with $\mathrm{CHI}$

in all the steps involved in the comprehension of the communicative act. No intermediate errors occurred.

The different pragmatic phenomena investigated, i.e. production and comprehension of standard communicative acts, deceit and irony, were rated on an increasing number of dimensions, i.e. expression act, actor's meaning, violation, and purpose. Thus, according to the specific pragmatic phenomena investigated, various patterns of intermediate errors emerged.

Table 5 displays the mean frequencies of occurrence of each pattern across the different tasks for both groups (CHI and controls) on comprehension tasks; Table 6 displays the mean frequencies of occurrence on production tasks. The means of the patterns identified for each group were calculated across all tasks.

- Insert Table 5 about here -

- Insert Table 6 about here -

By way of example, the absolute frequencies for linguistic comprehension of deceit in the CHI group were found to be as follows:

- Pattern I (totally wrong) $=5$

- $\quad$ Pattern II (intermediate errors) $=5$

- $\quad$ Pattern III (intermediate errors) $=2$

- $\quad$ Pattern IV (intermediate errors) $=17$

- $\quad$ Pattern V (correct) $=91$

Next, the mean frequencies were calculated by dividing each absolute frequency by 4 (i.e., the number of linguistic deceit comprehension tasks):

- $\quad$ Pattern $I=1.25$ 
Communicative errors in patients with $\mathrm{CHI}$

- $\quad$ Pattern II $=1.25$

- $\quad$ Pattern III $=0.5$

- $\quad$ Pattern IV $=4.25$

- Pattern $\mathrm{V}=22.75$

As shown in Table 5 and Table 6, intermediate patterns of responses occurred more frequently in the $\mathrm{CHI}$ group than in the control group. In other words, the $\mathrm{CHI}$ group made a higher number of intermediate errors, i.e., they failed to pass the last dimension (see Table 4), showing impairments at different levels of comprehension and production.

Having analyzed the data corresponding to the "Correct" dimension, this section focuses on participants' with CHI "intermediate errors".

Logistic regression analysis was performed to establish the effect of group (CHI vs. controls) on the occurrence of intermediate errors. Logistic regression predicts the outcome of a binary criterion variable (i.e., the occurrence vs. absence of intermediate errors) based on one or more predictor variables (in this case, group membership). Nagelkerke's $R^{2}$ was employed to evaluate the goodness of fit of the logistic regression models. Nagelkerke's $R^{2}$ is the logistic analogue of $R^{2}$ in linear regression, and quantifies the explanatory power of the independent variables as a whole. The values were thus dichotomized into "presence of intermediate errors" and "absence of intermediate errors". Group membership significantly predicted the occurrence of intermediate errors in participants' responses $\left(b=1.27, p<.0001, O R=3.572, R^{2}=\right.$ $.12)$.

An odds ratio (OR) of more than one indicated that group membership increases the occurrence of intermediate errors; specifically, being a member of the CHI group was associated with an increase of 3.572 times in the odds of committing errors. 
Communicative errors in patients with $\mathrm{CHI}$

The results were also comparable when considering each scale separately. Group membership significantly predicted the occurrence of intermediate errors on both the linguistic scale $\left(b=1.36, p<.0001, O R=3.912, R^{2}=.13\right)$ and the extralinguistic scale $\left(b=1.21, p<.0001, O R=3.368, R^{2}=.11\right)$. Moreover, being a member of the CHI group increased the odds of occurrence of intermediate errors on both comprehension tasks $\left(b=1.36, p<.0001, O R=3.912, R^{2}=.13\right)$ and production tasks $\left(b=1.19, p<.0001, O R=3.287, R^{2}=.11\right)$.

Considering each task separately (see Tables 5 and 6), group membership significantly predicted the occurrence of intermediate errors on the following pragmatic tasks: linguistic comprehension $\left(b=1.253, p=.03, O R=3.5, R^{2}=.11\right)$ and production of deceit $\left(b=1.604, p=.014, O R=4.971, R^{2}=.16\right)$, linguistic comprehension of irony $\left(b=2.037, p=.001, O R=7.667, R^{2}=.27\right)$, extralinguistic production of standard communicative acts $\left(b=2.093, p=.011, O R=8.105, R^{2}=\right.$ $.21)$, extralinguistic comprehension $\left(b=1.394, p=.011, O R=4.03, R^{2}=.14\right)$ and production of deceit $\left(b=2.277, p<.0001, O R=9.75, R^{2}=.3\right)$, and extralinguistic production of irony $\left(b=1.325, p=.044, O R=3.763, R^{2}=.11\right)$. The group membership predictor was not significant for: linguistic comprehension $(b=20.66, p$ $=.998)$ and production of standard communicative acts $(b=19.817, p=.998)$, linguistic production of irony $(b=.84, p=.157)$, extralinguistic comprehension of standard communicative acts $(b=19.817, p=.998)$, and extralinguistic comprehension of irony $(b=.981, p=.096)$. Table 7 displays a summary of the logistic regression analysis.

- Insert Table 7 about here - 
Communicative errors in patients with $\mathrm{CHI}$

Finally, Figure 1 displays the impairment profile of each participant in the $\mathrm{CHI}$ group. In this case, the number of times an intermediate pattern of errors occurred for each kind of task was calculated for each participant. More specifically, if a participant achieved intermediate patterns 3 times on the total of 4 items for the linguistic comprehension of deceit, she/he obtained $75 \%$ of intermediate errors.

- Insert Figure 1 about here -

\section{Discussion}

The aim of the present study was to provide a qualitative and quantitative description of specific pragmatic errors made by participants with $\mathrm{CHI}$ in the comprehension and production of standard (direct and indirect) communicative acts, deceit and irony, expressed through both the linguistic and extralinguistic modalities. The intention was to go beyond the traditional scoring procedure used in the majority of empirical studies available in the current literature (see for example Bara, Tirassa \& Zettin, 1997; Bara, Cutica \& Tirasaa, 200; Angeleri et al. 2008, Dardier et al. 2011; but for an exception see McDonald et al. 2003) which, for the sake of simplicity and reliability, treat performance on a communicative task as "passed" or "failed" on the basis of a dichotomous "zero" or "one" coding criterion. The novelty of the present study lies in the use of a fine-grained scoring procedure articulated on different dimensions of evaluation, on the basis of a specific theoretical framework, i.e. the Cognitive Pragmatics theory (Bara, 2010) and in placing the empirical data within a theory whose assumptions hold for both normally-developed (Angeleri, Bosco, Gabbatore, Bara \& Sacco, 2012) and brain-damaged subjects (Angeleri et al. 2008). 
Communicative errors in patients with $\mathrm{CHI}$

To obtain specific evaluation dimensions, during the administration of the experimental tasks the participants were asked to answer some specific questions designed to separately evaluate their ability to understand and produce the following aspects of a communicative act: (a) Expression act, that is the literal meaning of an utterance, (b) Actor's meaning, that is the actor's communicative intention, (c) Violation of cooperation, consisting in the capacity to understand that what is said is not true/not serious, as in the case of irony, and (d) Purpose of violation, consisting in the capacity to understand the reason why an actor produced a specific communicative act.

In line with our expectations (see Bosco et al., 2006), the results showed that some aspects of communicative impairment in participants with $\mathrm{CHI}$ are better described in terms of "intermediate errors" rather than in terms of "all-or-none" loss of ability, the concept according to which a communicative act is either understood/produced or not

Before analyzing the results concerning participants' intermediate errors following the new criteria described above, a preliminary analysis was conducted to compare $\mathrm{CHI}$ and control participants using the traditional coding system, that is, only considering the full comprehension/production of a communicative act. In line with the literature, the results showed that participants with $\mathrm{CHI}$ performed worse than controls on both the Linguistic and Extralinguistic scales, in both the comprehension and production of a communicative act, and in all the pragmatic phenomena investigated, i.e., standard (direct and indirect), irony and deceit. In particular the results of the present investigation are consistent with previous studies showing that participants with $\mathrm{CHI}$ perform worse, compared to controls, on the comprehension of standard acts (direct and indirect communicative acts), irony and deceit expressed 
using linguistic (Bara, Tirassa \& Zettin, 1997: McDonald, 2000; Martin \& McDonald, 2005) and extralinguistic modalities (Bara, Cutica \& Tirassa, 2001). Furthermore in line with Angeleri and colleagues (2008), the results of the present investigation showed that participants with $\mathrm{CHI}$ also perform worse, in comparison to normal controls, in the production of the same pragmatic phenomena produced using both the linguistic and extralinguistic modalities. This general alignment with previous studies suggests that the present data are reliable.

The novelty of the present study is that it focuses attention on participants' intermediate errors. Considering the participants' wrong answers - or, in other words, incorrect answers normally coded as "zero" - it makes a distinction between "totally wrong" answers and the presence of "intermediate errors". The presence of "intermediate errors" corresponds to the achievement of a pass in at least one of the intermediate steps in the comprehension/production process described by the Cognitive Pragmatics theory.

Participants with CHI produced a higher percentage of intermediate errors than the control group, as revealed by a logistic regression analysis in which group membership significantly predicted the occurrence of intermediate errors in participants' responses considering both the overall results and each scale (Linguistic vs. Extralinguistic) separately.

Group membership also significantly predicted the occurrence of intermediate errors in participants' responses when considering comprehension vs. production tasks separately. A more articulated pattern of results was obtained when considering each task separately: group membership significantly predicted the occurrence of intermediate errors in linguistic comprehension and production of deceit, linguistic comprehension of irony, extralinguistic production of standard communicative acts, 
Communicative errors in patients with $\mathrm{CHI}$

extralinguistic comprehension and production of deceit, and extralinguistic production of irony. By contrast, group membership was not a significant predictor of linguistic and extralinguistic comprehension and linguistic production of standard communicative acts, linguistic production and extralinguistic comprehension of irony. The lack of significance for these phenomena can be explained as follows. First, analyzing the different phenomena investigated separately made it possible to reduce the actual number of items analyzed. Second, most of the phenomena for which no significant difference emerged were those considered to be the easiest (that is standard communicative acts) and most difficult (namely the production of linguistic irony and the comprehension of extralinguistic irony; see Angeleri et al., 2008). As can be observed from performance by the control group, these tasks are also difficult for non-damaged individuals: a greater occurrence of intermediate patterns of errors was only observed in this group for the production of linguistic irony and comprehension of extralinguistic irony. Finally, the CHI participants were probably not a homogeneous group in their communicative performance; the present study refers to averaged data for individual communicative behaviors, as typically reported in experimental studies, which often have large within-group variability and inconsistent between-group differences (e.g., Angeleri et al., 2008; Body \& Perkins, 2004; Hein \& Turkstra, 2002; Turkstra, Ciccia, \& Seaton, 2003).

Our theoretical analysis does indeed hold, in principle, not only for participants with CHI but also for non-damaged individuals. Usually, however, normallydeveloped healthy people have a "ceiling" performance level, particularly on the simplest tasks such as standard communicative acts (Angeleri, et. al. 2012), and the comprehension/production of different communicative acts takes place directly in the 
Communicative errors in patients with $\mathrm{CHI}$

final stage of the process without that person's answers revealing any intermediate levels of comprehension/production.

Closed-head injury is interesting from this perspective because it does not involve one specific cerebral area, but, rather, it results in diffuse axonal injury, concerning all the cerebral networks involved in the communication process. The communicative deficit in participants with $\mathrm{CHI}$ results in neither a dichotomic impairment of communicative ability (i.e., full maintenance vs. full deficit) nor selective damage to one or more components. The results of the present study showed a graduated deficit in communicative ability, testified by the high frequency of intermediate errors in participants with $\mathrm{CHI}$ with respect to healthy controls, on all the pragmatic dimensions considered. This is in line with evidence from studies which have shown that pragmatic competence is not localized in a specific cerebral area, but involves several brain regions and connections, particularly on the frontal lobe (Douglas, 2010; Kasher et al., 1999; Stuss, Gallupp, \& Alexander, 2001).

Finally, some clinical considerations: Communication has a crucial role in setting and maintaining social relationships: impaired social ability represents one of the most destabilizing and invalidating sides of the condition (McDonald, Flanagan, Martin, \& Saunders, 2004). For this reason it appears to be important to comprehend where people with traumatic brain injury fail in their comprehension process, in order to investigate whether and which communicative abilities are intact. The theoretical and empirical analyses conducted in this study offer a fine-grained modality for describing clinical observations concerning the gravity of a participants' with CHI pragmatic deficits, for example it is possible to describe the gravity of a patient's deficit on the basis of his/her difficulty to understand/produce the expression act, or the actor's meaning, or the violation, and the purpose of a communicative act. 
Communicative errors in patients with $\mathrm{CHI}$

Communication is the expressive and receptive means through which it is possible to convey every form of clinical treatment, in both the psychotherapeutic and rehabilitative settings. For this reason it is necessary to have an in-depth understanding of the theoretical reasons that lead to communicative failures in people with $\mathrm{CHI}$, in order to develop rehabilitation programs that are effective in helping them to overcome their impairment and recover their communicative abilities in their everyday interactions. This study offers some suggestions concerning the development of rehabilitation treatment. For example, during the rehabilitation treatment the therapist could formulate specific prompts to the patient, i.e. "What could you/he say...", "What do you/he mean by sayng...", "What do you/does he wish to obtain by saying...", depending on the specific communicative problem, i.e. failure to comprehend/produce the expression act, the actor's meaning, the violation or the purpose of a communicative act. Such kind of suggestions could be systematically integrated in a more articulated and comprehensive rehabilitation treatment and contribute to increase communicative patient's ability. 
Communicative errors in patients with $\mathrm{CHI}$

Acknowledgements: This research was supported by Regione Piemonte, Project:

Institutions, Behaviour and Markets in Local and Global Settings (Project

IIINBEMA). The authors would like to thank Lorena Fonte, Viviana Leveratto, and Elena Scarsoglio for their contribution to data collection, and Alessandra Ruzzini for her assistance with selecting participants. 
Communicative errors in patients with $\mathrm{CHI}$

\section{References}

Adolphs, R. (2001). The neurobiology of social cognition. Current Opinion in Neurobiology, 11, 231-239.

Airenti, G., Bara, B. G., \& Colombetti, M. (1993a). Conversation and behavior games in the pragmatics of dialogue. Brain and Language, 17, 197-256.

Airenti, G., Bara, B. G., Colombetti, M., (1993b). Failures, exploitations and deceits in communication. Journal of Pragmatics, 20, 303-326.

Angeleri, R., Bosco F. M., Gabbatore, I., Bara, B. G., \& Sacco, K. (2012). Assessment Battery for Communication: Normative data. Behavior Research Methods, 44, 845-61.

Angeleri, R., Bosco, F. M., Zettin, M., Sacco, K., Colle, L., \& Bara, B. G. (2008). Communicative impairment in traumatic brain injury: A complete pragmatic assessment. Brain and Language, 107, 229-245.

Austin, J. L. (1962). How to do things with words. Oxford, UK: Oxford University Press.

Bara, B. G. (2010). Cognitive pragmatics. Cambridge, MA: MIT Press.

Bara, B. G., Cutica, I., \& Tirassa, M. (2001). Neuropragmatics: Extralinguistic communication after closed head injury. Brain and Language, 77, 72-94.

Bara, B. G., Tirassa, M. (2010) A mentalist framework for linguistic and extralinguistic communication. Linguistic and Philosophical Investigations, 9, 182-193.

Bara, B. G., Tirassa, M., \& Zettin, M. (1997). Neuropragmatics: Neuropsychological constraints on formal theories of dialogue. Brain and Language, 59, 7-49.

Bibby, H., \& McDonald, S. (2005). Theory of mind after traumatic brain injury. Neuropsychologia, 43, 99-114. 
Communicative errors in patients with $\mathrm{CHI}$

Body, R., \& Perkins, M. R. (2004). Validation of linguistic analyses in narrative discourse after traumatic brain injury. Brain Injury, 18, 707-724.

Bosco, F. M., Angeleri, R., Zuffranieri, M., Bara, B. G., \& Sacco, K. (2012). Assessment battery for communication: Development of two equivalent forms. Journal of Communication Disorders, 45, 290-303.

Bosco F.M., Colle L., De Fazio, S., Bono A., Ruberti, S., Tirassa M. (2009).

Th.o.m.a.s.: An exploratory assessment of Theory of Mind in schizophrenic subjects. Consciousness and Cognition, 18, 306-319.

Bosco F.M., Bucciarelli M., Bara B.G. (2004). The fundamental context categories in understanding communicative intentino. Journal of Pragmatics, 36, 467- 488.

Bosco F.M., Bucciarelli M. (2008). Simple and complex deceits and ironies. Journal of Pragmatics, 40, 583-607.

Bosco, F. M., Bucciarelli, M., \& Bara, B. G. (2006). Recognition and repair of communicative failures: A developmental perspective. Journal of Pragmatics, 38, 1398-1429.

Bosco, F. M. Bono, A., \& Bara, B. G. (2012). Recognition and repair of communicative failures: The interaction between theory of mind and cognitive complexity in schizophrenic patients, Journal of Communication Disorders, 45, 181-197.

Braun, C. M. J., Lissier, F., Baribeau, J. M. C., \& Ethier, M. (1989). Does severe traumatic closed head injury impair sense of humor? Brain Injury, 3, 345-354.

Carlomagno, S., Giannotti, S., Vorano, L., \& Marini, A. (2011). Discourse information content in non-aphasic adults with brain injury: A pilot study. Brain Injury, 25, 1010-1018. 
Communicative errors in patients with $\mathrm{CHI}$

Chapman, S. B. (1997). Cognitive-communication abilities in children with closed head injury. American Journal of Speech-Language Pathology, 6, 50-58.

Coelho, C. A. (2002). Story narratives of adults with closed head injury and nonbrain-injured adults: Influence of socioeconomic status, elicitation task, and executive functioning. Journal of Speech, Language, and Hearing Research, 45, $1232-1248$.

Coelho, C. A., Youse, K. M., Le, K. N., \& Feinn, R. (2003). Narrative and conversational discourse of adults with closed head injuries and non-braininjured adults: A discriminant analysis. Aphasiology, 17, 499-510.

Dardier, V., Bernicot, J., Delanoë, A., Vanberten, M., Fayada, C, Chevignard, M., Delaye, C., Laurent-Vannier, A \& Dubois B. (2011). Severe traumatic brain injury, frontal lesions, and social aspects of language use: A study of Frenchspeaking adults. Journal of Communication Disorders, 4, 359-378.

Dascal, M. (1985). The relevance of misunderstanding. In Dascal, M. (Ed.),

Dialogue: An interdisciplinary approach (pp. 441-459).

Amsterdam/Philadelphia: Jhon Benjamin.

De Renzi, E., \& Vignolo, L. A. (1962). The Token Test: A sensitive test to detect receptive disturbances in aphasics. Brain, 85, 665-678.

De Sousa, A., McDonald, S., Rushby, J., Li, S., Dimoska, A., \& James, C. (2010). Why don't you feel how I feel? Insight into the absence of empathy after severe traumatic brain injury. Neuropsychologia, 48, 3585-3595.

Docking, K., Murdoch, B. E., \& Jordan, F. M. (2000). Interpretation and comprehension of linguistic humor by adolescents with head injury: A group analysis. Brain Injury, 14, 89-108. 
Communicative errors in patients with $\mathrm{CHI}$

Douglas, J. M. (2010). Relation of executive functioning to pragmatic outcome following severe traumatic brain injury. Journal of Speech, Language, and Hearing Research, 53, 365-382.

Eslinger, P. J., Zappalà, G., Chakara, F., \& Barrett, A. M. (2007). Cognitive impairments after TBI. In N. D. Zasler, D. I. Katz, \& R. D. Zafonte (Eds.), Brain injury medicine (pp. 779-790). New York, NY: Demos.

Folstein, M., Folstein, S., \& McHugh, P. (1975). Mini-Mental State: A practical method for grading the cognitive state of patients for the clinicians. Journal of Psychiatric Research, 12, 189-198.

Gibbs, R. W. (1999). Interpreting what speakers say and implicate. Brain and Language, 68, 466-485.

Grice, H. P. (1975). Logic and Conversation. The William James Lectures, II. In Cole, P. and Morgan, J. L. (Eds.), Syntax and Semantics 3: Speech Acts. New York, NY: Academic Press.

Grice, P. (1989). Studies in the way of words. Cambridge, MA/London, UK: Harvard University Press.

Hartley, L. L., \& Jensen, P. J. (1991). Narrative and procedural discourse after closedhead injury. Brain Injury, 5, 267-285.

Hein, A., \& Turkstra, L. (2002). Cohesion, communication burden, and response adequacy in adolescent conversations. Advances in Speech-Language Pathology, 4, 1-8.

Holland, A. L. (1980). Communicative abilities in daily living. Baltimore, MD: University Park Press.

Holland, A. L., Frattali, C., \& Fromm, D. (1998). Communication activities of daily living (CADL-2). Austin, TX: Pro-Ed. 
Communicative errors in patients with $\mathrm{CHI}$

Huber, W., Poeck, K, Weniger, D., \& Willmes, K. (1983). Der Aachener Aphasie Test (AAT). Gottingen, DE: Hogrefe. Italian Version: Luzzatti, C., Willmes, K. \& De Bleser, R. (Eds.), 1996.

Johnson, J.E. \& Turkstra L.S. (2012). Inference in conversation of adults with traumatic brain injury. Brain Injury, 26, 1118-1126.

Kasher, A., Batori, G., Soroker, N., Graves, D., \& Zaidel, E. (1999). Effects of rightand left-hemisphere damage on understandingconversational implicatures. Brain and Language, 68, 566-590.

Kreuz, R. J., \& Roberts, R. M. (1993). When the collaboration fails: Consequences of pragmatic error in conversation. Journal of Pragmatics, 19, 239-252.

Landis, J., \& Koch, G. (1977). The measurement of observer agreement for categorical data. Biometrics, 33, 159-174.

Levinson F. C. (1983). Pragmatics. Cambridge, UK: Cambridge University Press.

Lezak, M. D., Howieson, D. B., \& Loring, D. W. (2004). Executive functions and motor performance. In M. D. Lezak (Ed.), Neuropsychological assessment (4th ed.) (pp. 611-646). New York, NY: Oxford University Press.

Marini, A., Galetto, V., Zampieri, E., Vorano, L., Zettin, M., Carlomagno, S. (2011). Narrative language in traumatic brain injury. Neuropsychologia, 49, 2904-2910.

McDonald, S. (1993). Viewing the brain sideways? Right hemisphere versus anterior models of non-aphasic language disorders. Aphasiology, 7, 535-549.

McDonald, S, (2000). Neuropsychological studies of sarcasm. Metaphor and Symbol, $15,85-98$.

McDonald, S. (2012). New frontiers in neuropsychological assessment: Assessing social perception using a standardised instrument, the Awareness of Social Inference Test. Australian Psychologist, 47, 39-48. 
Communicative errors in patients with $\mathrm{CHI}$

McDonald, S., Flanagan, S., Rollins, J., Kinch, J. (2003). TASIT: A new clinical tool for assessing social perception after traumatic brain injury. The Journal of Head Trauma Rehabilitation, 18, 219-236.

McDonald, S., \& Pearce, S. (1996). Clinical insight into pragmatic theory: Frontal lobe deficits and sarcasm. Brain and Language, 61, 88-104.

McDonald, S., \& Van Sommers, P. (1993). Pragmatic language skills after closed head injury: Ability to negotiate requests. Cognitive Neuropsychology, 10, 297315.

McDonald, S., Flanagan, S., Martin, I., \& Saunders, C. (2004). The ecological validity of TASIT: A test of social perception. Neuropsychological Rehabilitation, 14, 285-302.

Martin, I., \& McDonald, S. (2005). Evaluating the causes of impaired irony comprehension following traumatic brain injury. Aphasiology, 19, 712-730.

Mozeiko, J., Le, K., Coelho, C., Krueger, F., \& Grafman, J. (2011). The relationship of story grammar and executive function following TBI. Aphasiology, 25, 826835.

Pearce, S., McDonald, S., \& Coltheart, M. (1998). Interpreting ambiguous advertisements: The effect of frontal lobe damage. Brain and Cognition, 38, $150-164$.

Penn, C. (1988). The profiling of syntax and pragmatics in aphasia. Clinical Linguistics and Phonetics, 2, 179-207.

Prutting, C. A., \& Kirchner, D. (1987). A clinical appraisal of the pragmatic aspects of language. Journal of Speech and Hearing Disorders, 52, 105-119.

Russeaux, M., Vérigneaux, C., \& Kozlowski, O. (2010). An analysis of communication in conversation after severe traumatic brain injury. European Journal of Neurology, 17, 922-929. 
Communicative errors in patients with $\mathrm{CHI}$

Sacco, K., Angeleri, R., Bosco, F. M., Colle, L., Mate, D., \& Bara, B. G. (2008). Assessment Battery for Communication - $\mathrm{ABaCo}$ : A new instrument for the evaluation of pragmatic abilities. Journal of Cognitive Science, 9, 111-157.

Searle, J. R. (1969). Speech acts: An essay in the philosophy of language. London, UK: Cambridge University Press.

Stuss, D. T., Gallup, G.G., \& Alexander, M. P. (2001). The frontal lobes are necessary for 'theory of mind'. Brain, 124, 279-286.

Tate, R. L., Lulham, J. M., Broe, G. A., Strettles, B., \& Pfaff, A. (1989). Psychosocial outcome for the survivors of severe blunt head injury: The results from a consecutive series of 100 patients. Journal of Neurology, Neurosurgery, and Psychiatry, 52, 1128-1134.

Tirassa M., Bosco F.M., Colle L., (2006). Rethinking the ontogeny of mindreading. Consciousness and Cognition, 15, 197-217.

Tirassa M, Bosco F.M., Colle L. (2006). Sharedness and privateness in human early social life. Cognitive Systems Research, 7, 128-139.

Togher, L., Power, E., Tate, R., McDonald, S., \& Rietdijk, R. (2010). Measuring the social interactions of people with traumatic brain injury and their communication partners: The adapted Kagan scale. Aphasiology, 24, 914-927.

Turkstra, L. S., Brehm, S. E., Montgomery, E. B. (2006). Analysing conversational discourse after traumatic brain injury: Isn't it about time? Brain Impairment, 7, 234-245.

Turkstra, L. S., Ciccia, A. H., Seaton, C. (2003). Interactive behaviors in adolescent conversation dyads. Language, Speech and Hearing Services in Schools, 34, 117-127. 
Communicative errors in patients with $\mathrm{CHI}$

Turkstra, L. S., McDonald, S., \& DePompei, R. (2001). Social information processing in adolescents: Data from normally developing adolescents and preliminary data from their peers with traumatic brain injury. Journal of Head Trauma Rehabilitation, 16, 469-483.

Weigand, E. (1999). Misunderstanding: The standard case. Journal of Pragmatics, 31, $763-785$.

Winner, E., \& Gardner, H. (1977). Comprehension of metaphor in brain damaged patients. Brain, 100, 717-729.

Ylvisaker, M. (1998). Traumatic Brain Injury Rehabilitation: Children and Adolescents (2nd ed.). Boston, MA: Butterworth-Heinemann. 